\title{
Ambidexterity and Organizational Resilience of Telecommunication Firms in Port Harcourt, Rivers State
}

\author{
Onyinye Ogonna Onwughalu \\ Department of Management, Faculty of Management Sciences \\ University of Port Harcourt, Nigeria \\ Edwinah Amah \\ Department of Management, Faculty of Management Sciences \\ University of Port Harcourt, Nigeria
}

\begin{abstract}
This study examined the relationship between ambidexterity and organizational resilience among telecommunication firms operating in Port Harcourt, Rivers State. Cross sectional research design was adopted in studying the four selected telecommunication firms. The number of respondents engaged for this study is forty (40) functional unit managers at the head offices of the firms studied. From the field survey, we retrieved and analyzed forty (40) copies of questionnaire using Spearman's Rank order correlation coefficient statistical tool which was adopted in order to determine the relationship existing between the variables. The findings reveal that the dimensions of ambidexterity namely; exploration and exploitation exhibited significant relationship with organizational resilience. We then concluded that organizations that are ambidextrous in their leadership, structures/designs and in the utilization of dynamic capabilities possessed are resilient. This gave rise to our recommendation that organizations operating in this era of stiff competition should adopt exploitative and explorative strategies so as to effectively utilize their current competencies as well as being strategically positioned to take advantage of opportunities in the business environment in order to remain competitive and resilient.
\end{abstract}

Keywords: Ambidexterity, Exploitation, Exploration and Organizational Resilience

\section{INTRODUCTION}

Present day organizations operate in environments encumbered with unprecedented changes arising from the operations of competitors as well as other agents within the environment of business, for survival and sustainability therefore, individual firms ought to be equipped with requisite capabilities that will enable strategic response to the complexities prevalent in the environment. Customers' lamentation over the perennial issues of poor quality of services; this has led to in increased drop calls, depletions of credits, unsolicited short text messages (SMS), among others have necessitated that service providers (the telecommunication industry) develop approaches, practices and methodologies to proffer a lasting solution to the identified drawbacks. It is evident that firms who are able to speedily attend to these perceived needs will have competitive advantage over others and consequently become more resilient. Organizational resilience according to Holling and Gunderson (2002) is the amount of disturbance a given system can tolerate and still persist.

The concept - organizational resilience has attracted research interest from scholars focusing on differing cultures, contexts, sectors, countries adopting various explanatory variables; Umoh and Amah (2013) examined the effect of knowledge management on organizational resilience among manufacturing companies in Rivers State. Organizational resilience has been argued to respond significantly to management development practices among selected 
manufacturing firms in Port Harcourt (Umoh, Amah, \& Wokocha, 2014). Eketu and Ifionu (2015) in their study evaluated the impact of firms' collaborative behavior on enterprise resilience of banks in Nigeria. Organizational resilience has been predicted by mentoring (Jaja \& Amah, 2014) in the Nigerian manufacturing industry. Ikechukwu (2016) also investigated the association of innovation and organizational resilience among some manufacturing firms in Enugu State, Nigeria.

From the studies conducted above, it would interest us to know that none of the scholars had examined the relationship between ambidexterity and organizational resilience. Also none of the highlighted works was carried out on the Nigerian Telecommunications Industry thus resulting to an identified gap in literature. It is in attempt to bridge this gap that this study is embarked on to examine the relationship existing between ambidexterity in the management of resources and opportunities and organizational resilience of telecommunications firms operating in Port Harcourt City of Rivers State, Nigeria.

\section{THE CONCEPT OF AMBIDEXTERITY}

Ambidexterity in its literal meaning is the ability to use both hands with equal ease. 'Organizational ambidexterity' as a construct was first coined by Robert Duncan (1976) but March (1991) received the credit for having shed light into the concept by introducing the paradoxical components of ambidexterity which are 'exploration' and 'exploitation' which enables the organization to remain adaptive and creative in her given environment of business. The term connotes the balance between explorative and exploitative organizational strategies (Raisch \& Birkinshaw, 2008; Gibson \& Birkinshaw, 2004; He \& Wong, 2004; Benner \& Tushman, 2003). Thus short and long run success is determined by the ability of organizations to be both exploitative and explorative in the management of their competencies and opportunities as competitive advantage accrue to organizations that can actualize such a balance (Gibson \& Birkinshaw, 2004; He \& Wong, 2004).

Approaches highlighted by literature as enabling organizational ambidexterity can be seen as helping the organization manage its resources adequately and also helping it to be properly positioned to take advantage of opportunities in its environment of operation. Firm's resources (human and non human) include all the assets, capabilities, internal processes, firm's attributes, information and knowledge which are controlled by the firm that enables it conceive and implement strategies that improve efficiency and effectiveness (Barney, 1991). Resources at the disposal of an organization could be a potential source of competitive advantage. These resources are used in combination to develop products and services that are valuable to the customer. Porter (1981) describes firm's resources as strengths that firms can use to conceive of and implement their strategy.

Dimensions of ambidexterity are adapted from the study conducted by Mom, Van Den Bosch and Volberda (2007) to include; exploration (attempt towards creating variety of firm' experience) and exploitation (attempt towards creating reliability of firm's experience) as noted by Bontis, Crossan and Hulland (2002).

\section{EXPLORATIVE ACTIVITIES AND ORGANIZATIONAL RESILIENCE}

In the past two decades, change has been mentioned by executives of business institutions as a paradoxical factor that must be surmounted within the arena of business stated Palmer, Dunford and Akin (2009); paradoxical in the sense that it is both challenging to adhere to its demands and at the same time an important call to heed having that the business environment is in a state of constant transition; to continue in existence and thrive therefore, business 
executives are admonished to constantly align with the tides or risk the tendency of sinking by the waves (Higgs \& Rowland, 2005; Beer \& Nohria, 2000).

Suggested theories from extant research steer towards advocacy for change other than adaptation; so that organizations who are flexible and innovative will survive other than their rigid and non-innovative counterparts (Barnett \& Freeman, 2001; Pettigrew, Woodman, \& Cameron, 2001; Barnett \& Carroll, 1995); thus the modern workforce is required to adapt to these realities.

Repeated in organizational theory is the subject matter - 'ambidextrous enterprises'; such enterprises thrive and succeed in changing environments (Mickers, 2011); Gibson and Birkinshaw (2004) asserts that these business organizations align efficiently towards current business demands and also adapt effectively to changes in the business environment; thus this behavior is required for survival of business institutions (Jansen, van den Bosch, \& Volberda, 2005; Gibson \& Birkinshaw, 2004; He \& Wong, 2004) because revolutionary change is created and sustained by it (Tushman \& O'Reilly, 1996), competitive advantage is gained (Grant, 1996), and exploratory and exploitative innovations are made possible (Benner \& Tushman, 2003; Levinthal \& March, 1993; March, 1991).

Gibson and Birkinshaw (2004) created the complementary contextual (individual) ambidexterity which calls for individual employees to make choices between adaptionoriented and alignment-oriented activities. Rather than creating dual structures, contextual ambidexterity expects organizational leaders to create the context in which all individual employees are encouraged to divide their time between the two conflicting demands of adaption and alignment. Thus we hypothesize;

$\mathbf{H O}_{1}$ : Explorative activities of the firm have no significant relationship with organizational resilience of the firm

\section{EXPLOITATIVE ACTIVITIES AND ORGANIZATIONAL RESILIENCE}

Refinement of existing organizational competencies delineates exploitation while knowledge search in potential competencies and opportunities connote exploration (March, 1991). Firm's sustainable advantage relative to its competitiveness is dependent on how well a happy medium is stricken between the two sets of activities. Thus ambidexterity has been defined by authors and researchers as the dual pursuit of exploitative and explorative activities (Gibson \& Birkinshaw, 2004, He \& Wong, 2004; Tushman \& O’Reilly, 1996).

Tushman and O'Reilly (1996) showed exploitation as having to do with incremental changes and innovations within the organization. Lubatkin, Simsek, Ling and Veiga (2006) indicated ambidextrous organizations as those business units who are capable of exploiting existing competencies as well as exploring new opportunities with equal dexterity.

Effectiveness in explorative activities of the firm can result success in exploitative activities (Cao, Gedajlovic, \& Zhang, 2009). Accordingly, successful explorative activities can lead to improvement in exploitative activities of the business organization, because as knowledge is acquired from external sources and utilized, to exploit those potentials, more requisite competencies are required (Cao et al., 2009).

There is usually a trend towards greater certainties, greater speed, clarity and explicit knowledge of activities when striving for exploitation suggestive of the fact that less effort is allocated unto revolutionary innovative activities with its possible consequent outcome as 
knowledge obsolescence (Cao et al., 2009; Lubatkin et al., 2006). Moreover, idea continuity, formal procedures, routine, standards and repetition abounds within its scope thus accounting for corporate resilience (Cao et al., 2009; Gilsing, 2002).

Cao et al. (2009) in their study - "Unpacking organizational ambidexterity: Dimensions, contingencies, and synergistic effects", developed two dimensions in an attempt to illuminate the construct organizational ambidexterity; balance and combined dimensions of ambidexterity; regarding balance dimension, they noted that business organizations may be at the risk of failure for a lack of balance between explorative and exploitative activities, suggesting that striking a good balance between the series of activities will result in corporate resilience for the business organization.

Exploitation aims to find new applications for existing knowledge (Levinthal \& March, 1993). Exploration is an intrinsic part of a company's search for knowledge as it scouts for innovations that may be used in future applications, eventually providing for a positive interplay between exploration and exploitation.

The returns of exploration, however, are long term and uncertain, whereas those from exploitation are more short term, securing the resource base for investment in novel technologies (March, 1991); both seem to be necessary to maximize firm performance. Thus we hypothesize thus;

$\mathbf{H O}_{2}$ : Exploitative activities of the firm have no significant relationship with organizational resilience of the firm

\section{RELATIONSHIP BETWEEN AMBIDEXTERITY AND ORGANIZATIONAL RESILIENCE}

Business organizations who are ambidextrous are evolutional and at the same time revolution of organizational practices are their major concern (Tushman \& O'Reilly, 1996), they create and sustain good competitive positions (Grant, 1996), they are aptly responsive and efficient in operations (Hanssen-Bauer \& Snow, 1996), they constantly adapt to changes and also embed favorable outcomes (Volberda, 1996), they are both exploratory and exploitative (Benner \& Tushman, 2003; Levinthal \& March, 1993; March, 1991). The conflicting demands from task environments are adequately reconciled; effort is directed towards exploration of new opportunities as well as exploitation of existing organizational capabilities (Volberda \& Lewin, 2003). KFC, Pizza Hut, and Hardee's as chain organizations have been able to concurrently achieve innovativeness and control of such innovative outcomes (Bradach, 1997). Similarly, big corporations such as Hewlett-Packard (HP), Johnson \& Johnson, and Asea Brown Boveri (ABB) have successfully remained competitive by launching both incremental innovation and discontinuous innovation in well established markets and in emerging markets respectively (Tushman \& O'Reilly, 1996); these organizations operate in different industries, however each of them has been able to renew itself by simultaneously exploiting existing competencies and exploring new ones thus resulting to better organizational resilience stance manifested in firm's adaptive capacity.

The key driver of long term performance for modern business establishments becomes ambidexterity as a firm's ability to compete successfully in the long run depends on its ability to jointly engage in exploration activities and exploitation activities (Raisch \& Birkinshaw, 2008). To become ambidextrous therefore, business organizations need to strike a happy medium between conflicting demands (Raisch \& Birkinshaw, 2008). To this end, telecommunication firms in Nigeria are presently looking inwards and outwards to 
strategically exploit and explore possible opportunities that abound in their industrial environment of operation; this is made manifest through a wide variety of products and services churned out in the market alongside other background technological investigations directed at improving performance levels, with the consequent bottom line effects.

\section{METHODOLOGY}

This study adopted a cross sectional survey research design in engaging four telecommunication firms out of eighteen (18) registered with the Nigeria Communications Commission (NCC) which forms our accessible population, however our study units include the managerial employees of the firms having that our unit of analysis is organizational and such employees are to stand in proxy for the organization. The human resource department provided us the data on functional departments within the organization. Because the study elements were remarkably few in number; there was no need for sampling as we included all as our study objects. The instrument with which we elicited data from the respondents is the questionnaire (40 copies of questionnaire) and was analyzed using Spearman's Rank order coefficient of correlation statistical tool.

RESULTS AND DATA ANALYSES

Table 1: Spearman' rank order correlation coefficient: A test of association between the variables

\begin{tabular}{|c|c|c|c|c|c|}
\hline \multicolumn{6}{|c|}{ Correlations } \\
\hline & & & $\begin{array}{c}\text { Explorative } \\
\text { Activities }\end{array}$ & $\begin{array}{c}\text { Exploitative } \\
\text { Activities }\end{array}$ & $\begin{array}{c}\text { Org. } \\
\text { Resilience }\end{array}$ \\
\hline \multirow[t]{9}{*}{$\begin{array}{l}\text { Spearman's } \\
\text { rho }\end{array}$} & \multirow[t]{3}{*}{$\begin{array}{l}\text { Explorative } \\
\text { Activities }\end{array}$} & $\begin{array}{l}\text { Correlation } \\
\text { Coefficient }\end{array}$ & 1.000 & & \\
\hline & & Sig. (2-tailed) & . & & \\
\hline & & $\mathrm{N}$ & 40 & & \\
\hline & \multirow[t]{3}{*}{$\begin{array}{l}\text { Exploitative } \\
\text { Activities }\end{array}$} & $\begin{array}{l}\text { Correlation } \\
\text { Coefficient }\end{array}$ & $.907^{-2}$ & 1.000 & \\
\hline & & Sig. (2-tailed) & .000 & . & \\
\hline & & $N$ & 40 & 40 & \\
\hline & \multirow[t]{3}{*}{ Org. Resilience } & $\begin{array}{l}\text { Correlation } \\
\text { Coefficient }\end{array}$ & $.972^{-1}$ & $.884^{2-}$ & 1.000 \\
\hline & & Sig. (2-tailed) & .000 & .000 & \\
\hline & & $N$ & 40 & 40 & 40 \\
\hline
\end{tabular}

SPSS Output, Version 20 (2017 Field Result)

The Spearman rank correlation table above measures the strength of association between the variables as follows;

The result reported a strong positive correlation between explorative activities of the firm and organizational resilience ( $r h o=.972, n=40, p<0.01)$; thus we reject the null hypothesis $\left(\mathbf{H O}_{1}\right)$ to state that there is a significant relationship between explorative activities of business organizations and their resilience stance.

The result also showed a strong positive correlation between exploitative activities of the organization and organizational resilience (rho $=.884, \mathrm{n}=40, \mathrm{p}<0.01$ ); this results to the non acceptance of the stated null hypothesis $\left(\mathbf{H O}_{2}\right)$ to state that there is significant relationship between exploitative activities of the firms and enhanced corporate resilience. 
Table 3: Model Summary

\begin{tabular}{|l|c|c|c|c|}
\hline \multicolumn{5}{|c|}{ Model Summary } \\
\hline Model & $\mathrm{R}$ & R Square & $\begin{array}{c}\text { Adjusted R } \\
\text { Square }\end{array}$ & $\begin{array}{c}\text { Std. Error of the } \\
\text { Estimate }\end{array}$ \\
\hline 1 & $.941^{\mathrm{a}}$ & .885 & \multicolumn{3}{c|}{$\mathbf{8 7 9}$} & 2.461 \\
\hline \multicolumn{5}{|c|}{ a. Predictors: (Constant), Exploitative Activities, Explorative Activities } \\
\hline
\end{tabular}

SPSS Output, Version 20 (2017 Field result)

The model summary reports a correlation coefficient value of $.941^{\text {a }}$ for the dimensions of ambidexterity (explorative and exploitative activities) indicating that there exists a positive association between the dimensions and organizational resilience of firms, the Adjusted $\mathrm{R}$ Square value of .885 (85.5\%) represents the coefficient of determination which is the explained variation in organizational resilience as accounted for by explorative and exploitative activities of the firm; indicative of the fact that corporate resilience stance firms can be enhanced by being ambidextrous.

\section{DISCUSSION OF FINDINGS}

The result of the tested $\mathbf{H O}_{1}$ suggests that there exists significant relationship between firm's explorative activities and organizational resilience. This agrees with the opinion Cao et al. (2009) as they held that exploration activities delineate firm's orientation towards innovativeness with regards to the introduction of new products and markets, introduction of new generation of processes, widened range of product and services offerings thus diversifications into new markets, and entering new technological fields which will ultimately improve the firm's adaptive capacity in the environment of operation.

Also the result of the tested $\mathbf{H O}_{2}$ showed that significant relationship exists between firm's exploitative activities and organizational resilience; this finding is supported by Popadiuk and Bido (2016) in asserting that explicit knowledge is more present in exploitation, and there is an idea of continuity, routine, standards and repetition which would increase efficiency in operations over time. In addition, Turner and Lee-Kelley (2012) advocated that adding competencies and skills would ultimately increase the possibility of rewards for the organization as a whole.

\section{CONCLUSION}

Present day organizations require ambidextrous leaders and managers with requisite capacities and competencies need to be optimally exploited alongside exploring into potentials existent within the environment of business. The study revealed the role of leaders of business organizations in instituting structures that are consistently flexible, organic and one that is permeable allowing for constant alignment and responsiveness to changes in the business environment through explorative and exploitative activities.

Congruence between the firm's strategy and its environment is enhanced by dynamic capabilities possessed by organizational leaders thus enabling the competitiveness building, integrating and reconfiguring resources to maintain desirable performance outcomes in the face of high volatility in the business arena; this view is in consonance with Helfat (2000).

\section{RECOMMENDATIONS}

From the research analysis and conclusions above, the following recommendations are made for the benefit of telecommunication firms alongside other institutions; 
Organizational leaders should acquire traits that would enable ambidexterity, because the trajectories of any given organization are communicated by these leaders who directly influence performance outcomes.

Telecommunication firms should maintain a very flexible structure that allows for speedy responsiveness to the demands of their customers as well as strategic response to their competitors; by exploiting existing competencies as well as exploring into possible opportunities in order to improve performance of the organization.

\section{References}

Barnett, W. P., \& Carroll, G. R. (1995). modeling internal organizational change. Annual Review of Sociology, 21, 217-236.

Barnett, W. P., \& Freeman, J. (2001). Too much of a good thing? Product proliferation and organizational failure. Organization Science, 5, 539-558.

Barney, J. B. (1991). Firm resources and sustained competitive advantage. Journal of Management, 17, 99-120.

Beer, M., \& Nohria, M. (2000). Cracking the code of change. Harvard Business Review, 78(3), 133-41.

Benner, M. J., \& Tushman, M. L. (2003). Exploitation, exploration, and process management: The productivity dilemma revisited. Academy of Management Review, 28, 238-256.

Bontis, N., Crossan, M., \& Hulland, J. (2002). Managing an organizational learning system by aligning stocks and flows. Journal of Management Studies, 39, 437-69.

Bradach, J. L. (1997). Using the plural form in the management of restaurant Chains. Administrative Science Quarterly, 42, 276-303.

Cao, Q., Gedajlovic, E., \& Zhang, H. (2009). Unpacking organizational ambidexterity: Dimensions, contingencies and synergistic effects. Organization Science, 20(4), 781-796.

Eketu, C. A., \& Ifionu, E.P. (2015). Firms' collaborative behavior and enterprise resilience among banks in Nigeria. The International Journal of Business \& Management, 3(9), 27-33.

Gibson, C. B., \& Birkinshaw, J. (2004). The antecedents, consequences and mediating role of organizational ambidexterity. Academy of Management Journal, 47, 209-226.

Gilsing, V. A. (2002). Co-evolution of exploration \& exploitation in a sectoral system of innovation. Retrieved from http://www.druid.dk/conferences/winter2002/gallery/gilsing.pdf

Grant, A. M. (1996). Towards a knowledge-based theory of the firm. Strategic Management Journal, 17, 109-122.

Hassen-Bauer, J., \& Snow, C. C. (1996). Responding to hyper competition: The structure and processes of a regional learning network organization. Organization Science, 7(4), 1-12.

He, Z. L., \& Wong, P. K. (2004). Exploration vs. exploitation: An empirical test of the ambidexterity hypothesis. Organization Science, 15, 481-494.

Helfat, C. E. (2000). Guest editor's introduction to the special issue: The evolution of firm. Strategic Management Journal, 21(10/11), 955-960.

Higgs, M. J., \& Rowland, D. (2005). All changes great and small: Exploring approaches to change and its leadership. Change Management Journal, 5(2), 121-151.

Holling, C. S., \& Gunderson, L. H. (2002). Resilience and adaptive cycles: Understanding transformations in human and natural systems. Washington, DC: Island Press.

Ikechukwu, E. U. (2016). Innovation and organizational resilience in selected manufacturing firms in Enugu State, Nigeria.

Jaja, S. A., \& Amah, E. (2014). Mentoring and organizational resilience: A study of manufacturing companies in Rivers State. IOSR Journal of Business and Management (IOSR-JBM), 16(10), 1-9.

Jansen, J. J. P., van den Bosch, F. A. J., \& Volberda, H. W. (2005). Exploratory innovation, exploitative innovation, and ambidexterity: The impact of environmental and organizational antecedents. Schmalenbach Business Review, $57,351-363$.

Levinthal, D. A., \& March, J. G. (1993). The myopia of learning. Strategic Management Journal, 14(2), 95-112. 
Lubatkin, M. H., Simsek, Z., Ling, Y., \& Veiga, J. F. (2006). Ambidexterity and performance in small-to-medium sized firms: The pivotal role of TMT behavioral integration. Journal of Management, 32, 1-17.

March, J. G. (1991). Exploration and exploitation in organizational learning. Organization Science, 2, 71-87.

Mickers, A. A. F. (2011). Leading organizational change in ambidextrous environments: Insight in the use of contextual ambidexterity in SMEs to increase commitment to change. Department Organization \& Strategy Strategic Management, Tilburg University.

Mom, T. J. M., Van Den Bosch, F. A. J., \& Volberda, H. W. (2007). Investigating managers' exploration and exploitation activities: The influence of top-down, bottom-up and horizontal knowledge inflows. Journal of Management Studies, 44(6), 910-931.

Palmer, I., Dunford, R., \& Akin, G. (2009). Managing organizational change: A multi-perspective approach (2nd ed.). New York: McGraw-Hill.

Pettigrew, A. M., Woodman, R. W., \& Cameron, K. (2001). Studying organizational change and development: Challenges for future work. Academy of Management Journal, 44, 697-713.

Popadiuk, S., \& Bido, D. (2016). Exploration, exploitation and organizational coordination mechanisms. RAC, Rio de Janeiro, 20(2), 238-260.

Porter, M. E. (1981). Competitive advantage. New York: Free Press.

Raisch, S., \& Birkinshaw, J. (2008). Organizational ambidexterity: Antecedents, outcomes, and moderators. Journal of Management, 34(3), 375-409.

Turner, N., \& Lee-Kelley, L. (2012). Unpacking the theory on ambidexterity: An illustrative case on the managerial architectures, mechanisms and dynamics. Management Learning, 44(2), 179-196.

Tushman, M. L., \& O’Reilly, C. A. (1996). Ambidextrous organizations: Managing evolutionary and revolutionary change. California Management Review, 38, 8-30.

Umoh, G. I., \& Amah, E. (2013). Knowledge management and organizational resilience in Nigerian manufacturing organizations. The International Institute for Science, Technology and Education (IISTE), 3(9), 104-120.

Umoh, G.I., Amah, E., \& Wokocha, H. I. (2014). Management development and organizational resilience: A case study of some selected manufacturing firms in Rivers State, Nigeria. IOSR Journal of Business and Management (IOSR-JBM), 16(2), 7-16.

Volberda, H. W. (1996). Toward the flexible form: How to remain vital in hypercompetitive environments. Organization Science, 7, 359-374.

Volberda, H. W., \& Lewin, A. Y. (2003). Co-evolutionary dynamics within and between firms: From evolution to coevolution. Journal of Management Studies, 40(8), 2105-2130. 